\title{
LA INTUICIÓN-ESCUCHA EN EL ENCUENTRO CON EL OTRO
}

\section{THE INTUITION-LISTENING TO IN THE ENCOUNTER WITH THE OTHER}

\author{
Carlos Alberto Vargas Pacheco \\ Universidad Nacional Autónoma de México \\ caralvap@comunidad.unam.mx
}

RECIBIDO: 14 DE NOVIEMBRE DE 2018

ACEPTADO: 7 DE ENERO DE 2019

Resumen: El presente artículo ofrece una introducción a la noción de intuiciónescucha como herramienta para la consultoría filosófica. Para explicar dicha idea, se analizarán las nociones de intuición y escucha, respectivamente, para justificar el modo en que la noción propuesta se compone y puede operar. Se describirán brevemente algunos pasos elementales para poder desarrollar la intuición-escucha y se señalarán algunos antecedentes dentro de la tradición filosófica de occidente, donde es posible rastrear la noción propuesta.

Palabras clave: diálogo, alteridad, silencio, atención, encuentro.

\begin{abstract}
This paper offers an introduction of the idea intuition-listening as a tool for philosophical consulting. To explain that notion, I'm going to analyze the ideas of intuition and listening separately, in order to justify the concept of intuition-listening. Also, I will show a few steps to develop the practice of intuition-listening and the backgrounds of this notion in western philosophy tradition.
\end{abstract}

Keywords: dialogue, alterity, silence, attention, encounter.

\section{Introducción}

En los días que corren se ha consolidado una forma de ejercer la filosofía que trasciende los espacios académicos y recupera uno de sus signos originarios: ser un modo terapéutico de la vida humana. 
Lo anterior, innegablemente, es un fenómeno muy saludable para la propia filosofía pues, con ello, este viejo quehacer retoma una de sus dimensiones originarias. En efecto, en los albores del quehacer filosófico, éste no se limitaba ni reducía a un acto meramente intelectual. Ciertamente, la filosofía se ha caracterizado por la formación del ejercicio racional, pero en sus orígenes esto se efectuaba con miras a alcanzar una vida buena, esto es, una vida orientada por la prudencia, la observación, el análisis y la toma de decisiones meditadas con el fin de habitar la existencia de forma serena. Hallarse en paz podría ser la fórmula que, acaso, se acerque más al objetivo que perseguían las múltiples escuelas filosóficas del mundo heleno antiguo.

Es evidente que los seres humanos del mundo contemporáneo se encuentran en una situación vital distinta a la que envolvió a los pioneros de la filosofía griega. Pero aquello de alcanzar una vida apacible, que permita el sosiego en el ánimo y la templanza ante circunstancias adversas, innegablemente sigue siendo una aspiración de cualquier individuo, sobre todo en un mundo que se halla saturado de complejidades, circunstancias tensas, violencia y continuo estrés. Así pues, la recuperación del carácter terapéuticofilosófico para desarrollar habilidades que le permitan al individuo llevar una vida sosegada, a pesar del vértigo de la existencia del mundo actual, hace de la consultoría filosófica una labor muy fecunda y afortunada en la que los filósofos profesionales pueden incidir.

Por supuesto, se cuenta ahora con diversas perspectivas y dinámicas para desarrollar el trabajo concreto de la consultoría. En este sentido, es indispensable reconocer los múltiples enfoques que, en el presente, se han generado para realizar la práctica de la consultoría filosófica. Y, en medio de tal riqueza, el presente texto busca ofrecer una reflexión teórica que puede ampliar las consideraciones y las diversas prácticas de la consultoría. La meditación que a continuación se ofrece busca realzar un elemento 
que, muchas veces de manera implícita, se halla presente en la relación efectiva entre el filósofo y el consultante. Dicho elemento es el que se denominará intuición-escucha, y se tratará de mostrar que la consideración sobre dicho elemento por parte del filósofo, le permite reconocer la presencia de elementos subyacentes, aunque no siempre expresados verbalmente, por el consultante.

\section{Al encuentro con el otro}

En el encuentro con el otro siempre se muestra una singular paradoja. Por un lado, se trata del reconocimiento de un ser afín a uno mismo; es la presencia de un cuerpo semejante al propio que ofrece signos claros de envolver una mente que piensa, recuerda, proyecta, fantasea y quiere. El otro se presenta como alguien radicalmente afín, ontológicamente común con uno mismo, al punto que se puede entablar comunicación pues se reconoce que el otro cuenta con un lenguaje incluso si no se trata del mismo idioma. En este sentido, como ya dijera Platón en el Banquete, cada individuo es símbolo de otro ${ }^{1}$ y, por ende, complementario, familiar y enriquecedor del propio ser. Pero, por otro lado, ese otro que es complemento de uno mismo, a pesar de ser tan semejante, es radicalmente distinto. La singularidad del alter ego es inigualable. Por ello, el cúmulo de pensamientos, interpretaciones, recuerdos y deseos nunca pueden ser idénticas entre unos y otros. Así, siendo el otro tan cercano ontológicamente, sin embargo, es también lejano por la forma específica de su singularidad. Cercanía y lejanía, familiaridad y extrañeza coinciden, pues, en el encuentro con el otro, encuentro paradójico por ser a la vez tan cotidiano y enigmático.

Por esta situación ambivalente que se le presenta a los seres humanos todo el tiempo, las relaciones interpersonales que

\footnotetext{
${ }^{1}$ Platón: Banquete $191 \mathrm{c}-\mathrm{d}$.
} 
acontecen día con día son sumamente complejas. Como se sabe, en el contacto entre unos y otros hay coincidencias y discrepancias, puntos de acuerdo y desacuerdos ideológicos, apertura o ruptura emocional y un muy largo etcétera. En este océano infinito de la paradoja común-distinto que supone el habitar humano es en donde se despliega la existencia efectiva de los individuos. Naturalmente, no se cuenta con manuales ni reglas que informen a las personas sobre cómo proceder en el encuentro con los demás. Y, aunque haya quienes consideren que la moral o las leyes fungen como los reguladores del comportamiento interhumano, lo cierto es que esos dos ámbitos no son suficientes para atenuar el vértigo que siempre acontece en el encuentro con el otro.

Desde antiguo, el encuentro con la alteridad ha sido una de las principales preocupaciones de la filosofía. ${ }^{2} \mathrm{Ha}$ habido, por lo mismo, múltiples teorías que han reflexionado en torno a los modos en los que el vínculo con los demás pueda ser armónico, sin negar la presencia de los momentos conflictivos entre humanos. El cúmulo de estas reflexiones, a pesar de haber sido pensadas desde hace mucho tiempo, no dejan de tener vigencia, pues la comunión entre los individuos sigue entrañando, esencialmente, los mismos problemas hoy, que en el pasado. Por ello, es innegable que la filosofía, a través del ejercicio de la consultoría, es capaz de ayudar a los hombres y mujeres del presente, para aprender a comprender la complejidad que ha supuesto y sigue suponiendo el encuentro entre unos y otros.

\footnotetext{
${ }^{2}$ En este punto hay una coincidencia con Óscar Brenifier, quien sostiene que "la práctica filosófica implica una confrontación con la alteridad, una visión con otra. Consiste en ejercer el pensamiento entendido en el sentido de desdoblamiento (dédoublement); como un diálogo con uno mismo, con el otro, con el mundo, con la verdad.” Vid. Brenifier "¿Puede la filosofía convertirse en una práctica?", p. 222. Disponible en línea en: https://www.ciudadredonda.org/admin/upload/files/1cr_t_adjuntos_269.pdf (consultado en línea el 4 de enero de 2019).
} 


\section{El lógos como unidad y singularidad del ser humano}

Pensaba el viejo Heráclito que lo común a todos los seres humanos es el lógos. Y aunque el de Éfeso se refería con ello a que hay un orden en común de la realidad ${ }^{3}$, es posible reconocer también que la palabra es aquello que refrenda la comunidad ontológica de lo humano, a la vez que permite dar expresión a las singularidades de cada miembro de dicha comunidad. En efecto, es por mor de la palabra que la paradoja del encuentro con el otro se supera. En el acto de hablar el otro anuncia su modo de ver lo que le pasa. En la exposición narrativa, cada uno de los individuos exterioriza siempre una visión del mundo, es decir, una forma específica de declarar lo que ocurre en el entorno, una manera de valorar los acontecimientos y la presencia de uno mismo en ellos, una historia cultural que lo soporta, un modo de esperar el porvenir y, por supuesto, una forma única de sentir el incontenible devenir de la existencia. La palabra, pues, expresa el modo específico de una singularidad, pues el lógos no es sólo la implementación de una estructura lingüística, sino la expresividad de un sentido de lo humano que, aunque rotundamente singular, sin embargo, es perfectamente comprensible por los demás, pues no se trata nunca de algo absolutamente extraño. Como ya decía Terencio, siendo hombre "nada de lo humano me es ajeno." " La comunidad de lo humano, entonces, se manifiesta por la palabra. Pero también, la expresión de una singularidad, gracias al lógos, halla cobijo al tiempo que enriquece a la comunidad de ser de lo humano. Como pensaba Eduardo Nicol —filósofo catalán-mexicano del siglo pasado- el hombre es el ser de la expresión y del lógos: común y singular al mismo tiempo, un ser absolutamente irrepetible $\mathrm{y}$,

\footnotetext{
${ }^{3}$ Heráclito: DK B1, B2, B50.

${ }^{4}$ Terencio: El atormentado. Acto I, v. 77.
} 
precisamente por ello, afín y complementario al resto de humanos que habitan el mundo. ${ }^{5}$

El poder de la palabra, entonces, consiste en ser el medio por el cual se expone un modo de ver lo real. Podría decirse, como ya lo indicaba Nicol, que todo lógos es diá-lógos: es el modo a través del cual se expone lo que se intuye, es decir, lo que se ve y comprende de manera cotidiana. Desde luego, alguien podría decir que el modo de ver y el modo de comprender no es inmediato en sentido estricto, pues siempre actúa una cierta mediación. Es más, a veces, el propio lenguaje funciona como algo limitante para poder transmitir lo que alguien ve. Pero, aunque ello fuese así, lo cierto es que en el habla o en la articulación de la palabra se quiere mostrar una forma específica del mirar: la intuición de lo que se vive, aun cuando no se exprese cabalmente en las palabras, se insinúa en el puñado de vocablos que se empleen. Por ello, en la articulación del lógos se deja ver lo intuido por el individuo, incluso más allá de lo que sus palabras específicas dejan ver.

\section{La intuición: lo in-visible en el diálogo}

En este punto conviene aclarar un poco más cómo se entiende aquí la intuición. La palabra intuición proviene del verbo latino intueor y su significado se refiere a las acciones de pensar, contemplar y mirar detalladamente ${ }^{6}$. El verbo intueor está compuesto, a su vez, del prefijo in que indica interioridad y el verbo tueor que significa mirar, guardar, velar, observar. ${ }^{7}$ La idea que trata de capturar el

${ }^{5}$ Cf. Nicol, Eduardo. Metafísica de la expresión. FCE, México, 2003. Passim. Cf. Diccionario en línea Lexica lingua. http://www.lexica.linguax.com/forc.php?searchedLG=Intueor Consultado en línea el 10 de abril de 2018.

$7 \quad C f$. Ibid. http://www.lexica.linguax.com/forc.php?searchedLG=Tueor Consultado en línea el 13 de abril de 2018. 
término en cuestión es la de mirar o contemplar desde y por dentro. Se trata de la captación inmediata del modo en que se hacen presente las cosas en uno mismo. La intuición es, por ello, el modo en el cual se abraza y mantiene lo que ocurre, por un lado, y también el material que da de qué hablar con uno mismo y con los demás, por otro. Esa vivencia interna y silenciosa de comprensión de lo que hay es a lo se refiere la noción de intuición. Dicha vivencia acontece constantemente, pero no siempre se le tiene presente, pues la facultad racional interviene en la comprensión intuitiva envolviéndola en estructuras conceptuales y formas específicas para aclarar, lógicamente, el torrente de impresiones que se han vivido. Puesto que la facultad racional tiende a recubrir conceptualmente a la intuición, ésta siempre queda detrás de las estructuras racionales, pero nunca es anulada del todo.

En relación con esto último es interesante observar que el filósofo francés, Henri Bergson, ya contaba con una opinión cercana a la que aquí se postula, aunque el autor analizaba el fenómeno de la intuición en relación con la labor filosófica. En efecto, cuando el pensador francés reflexiona sobre lo que él denominó como intuición filosófica, señala que las teorías y sistematizaciones que los filósofos llevan a cabo son formulaciones complejas que envuelven una simplicidad fundante. Dicha simplicidad, no obstante, siempre escapa y, por decirlo de algún modo, se esconde en el fondo de toda la articulación conceptual de una determinada teoría filosófica. Pero, continúa pensando Bergson, es factible navegar por las aguas teóricas de un pensador, al punto de atisbar, aunque sea por un instante, aquella vivencia simple que ha promovido el pensamiento del filósofo: la intuición de la que ha partido para darle mayor explicación y expresión verbal. Declara, al respecto Bergson:

¿Cuál es esa intuición? Si el filósofo no ha podido dar su fórmula, tampoco nosotros lo lograremos. Pero lo que llegaremos a asir y fijar 
es una cierta imagen intermedia entre la simplicidad de la intuición y la complejidad de las abstracciones que la expresan, imagen huyente y [evanescente], que acosa, inadvertida acaso, el espíritu del filósofo, que le sigue como su sombra a través de todas las vueltas y revueltas de su pensamiento, y que, si no es la intuición misma, se le aproxima mucho más que la expresión conceptual, necesariamente simbólica, al cual la intuición debe recurrir para dar "explicaciones". 8

Las ideas de Bergson no necesariamente se acotan al desarrollo teórico de los filósofos. En realidad, la intención de expresar con palabras lo que se ha vivido es un fenómeno que le ocurre a cualquier ser humano. Es cierto, desde luego, que no todos los individuos formulan una teoría en relación con lo que se intuye, pero el puro acto de tratar de darle expresión a la intuición es una actividad humana general, sin lugar a dudas. Y es que, la intuición es el percatarse de algo que pasa ${ }^{9}$, lo cual, claramente, le ocurre a quien sea. ${ }^{10}$ Ciertamente, la intuición se presenta, como piensa

${ }^{8}$ Bergson, Henri. Introducción a la metafisica Porrúa, México, 2009, p. 42. He colocado la palabra evanescente entre corchetes por considerarla más adecuada al original francés. Puede cotejarse la traducción con la versión original francesa que dice así: "Quelle est cette intuition? Si le philosophe n'a pas pu en donner la formule, ce n'est pas nous qui y réussirons. Mais ce que nous arriverons à ressaisir et à fixer, c'est une certaine image intermédiaire entre la simplicité de l'intuition concrète et la complexité des abstractions qui la traduisent, image fuyante et évanouissante, qui hante, inaperçue peut-être, l'esprit du philosophe, qui le suit comme son ombre à travers les tours et détours de sa pensée, et qui, si elle n'est pas l'intuition même, s'en rapproche beaucoup plus que l'expression conceptuelle, nécessairement symbolique, à laquelle l'intuition doit recourir pour fournir des «explications»". Henri Bergson. Intégrale des œuvres. Edición Kindle. Posición en Kindle: 24459-24464.

${ }^{9} \mathrm{Y}$ este algo, desde luego, no se reduce sólo a una cosa. Lo que pasa puede ser una cosa singular, un conjunto de objetos, una situación que congrega diversos objetos y personas relacionadas entre sí, un recuerdo que asalta al individuo, una emoción de la que no se puede dar suficiente explicación, una expectativa o una fantasía. En suma, cualquier tipo de vivencia que acontezca en cada uno de nosotros es algo que pasa.

${ }^{10}$ En la misma dirección, aunque sin referirse a la intuición apunta el filósofo 
Bergson, bajo el aspecto de una comprensión que todavía no encuentra las palabras adecuadas para ser expuesta ante uno mismo $\mathrm{y}$ ante otro. En este sentido, cabe postular que la intuición es aquello que im-pulsa la articulación de la palabra, pues en la captación que realiza un individuo de todo cuanto le ocurre adviene la urgencia de darle sentido, de buscar un orden que organice lo que ha captado. De aquí que lo intuición sea lo que brinda el material del lenguaje y, con ello, que la palabra se convierta en la expresión de aquello que se ha impreso en uno mismo. Sin embargo, el torrente de todo cuanto le pasa a alguien, eso que se capta en todo momento, no queda cabalmente integrado en la palabra. Por ello, a pesar de que se puede declarar, incluso con suma precisión lo que le pasa a uno, siempre hay algo que se escapa al lenguaje y que encuentra expresión por otros medios, que no son siempre lingüísticos (por ejemplo, a través de gestos, de pausas, del ritmo mismo en que se expone el lenguaje). En este

Ran Lahav, quien afirma: "nuestra comprensión de los problemas filosóficos no emerge sólo de nuestro pensamiento racional, como los filósofos suelen pensar. Si eso fuera el caso, sería un misterio averiguar por qué individuos distintos, con la misma capacidad racional, podrían tener opiniones filosóficas diferentes. Frente a esto, nuestros entendimientos son nutridos generalmente por otros aspectos de nuestro ser, como nuestra personalidad. Más interesante aún, es el hecho de que nuestro entendimiento también es influido e inspirado por estados internos de corto plazo, como las experiencias recientes, e, incluso, sentimientos $\mathrm{y}$ estados de ánimo. [[...] our understandings of philosophical issues do not emerge only from our rational thinking, as philosophers sometimes like to think. If this was the case, it would have been a mystery why different individuals who are equally rational have different philosophical opinions. Rather, our understandings are often nurtured by other aspects of our being, such as our personality traits. More interestingly, our understandings are also influenced and inspired by short-term inner states such as recent experiences and even feelings and moods.]" Vid. Ran Lahva. "Philosophical Practice: Have we gone far enough?", pp. 16-17 disponible en http://www.society-for-philosophy-inpractice.org/journal/pdf/9-2\%20013\%20Lahav\%20-\%20Far\%20enough.pdf (consultado el 4 de enero de 2019). La traducción es mía. 
sentido, lo que se comunica al otro - y también a uno mismomediante la palabra es algo que permite la comunicación de unos con otros, pero, en esa vinculación con el prójimo, junto con lo expuesto verbalmente en el diálogo, se da el indicio de algo que no queda dicho, que no es declarado prístinamente y que, no obstante, se insinúa en las palabras empleadas. De este modo, resulta que hablar no basta para adentrarse en el otro. Hay que aprender a comprender lo intuido que no se muestra de manera patente en el diálogo. Hay que surcar más allá de la palabra compartida con el otro.

\section{Presencia de la escucha}

Decía el maestro Heráclito que "Sin saber escuchar, tampoco pueden hablar". ${ }^{11}$ Este breve fragmento señala una idea que, aunque parece obvia, muchas veces deja de atenderse: la necesidad de guardar silencio con el fin de escuchar al otro para poder decir algo con sentido. En el encuentro dialógico con el otro, la escucha es fundamental. Y lo es, principalmente, en virtud de que al atender a la palabra expuesta y hacer el esfuerzo por ver aquello de lo que habla el otro es posible adentrarse en el modo de comprender las cosas que el interlocutor expone. Ahora bien, aun cuando parece claro a qué se refiere la acción de escuchar, resulta conviene inquirir por los orígenes de esta actividad. La propia etimología de escuchar posee, hasta hoy, resonancias significativas. El término procede del latín auscultare ${ }^{12}$ e indica la acción de prestar oídos ante el entorno y, desde luego, ante lo expresado por alguien más.

${ }^{11}$ Heráclito. DK 19.

${ }_{12}$ Cf. Diccionario en linea Lexica Lingua. http://www.lexica.linguax.com/forc.php?searchedLG=auscultare Consultado en línea el 15 de abril de 2018. 
Se trata de hallarse dispuesto a captar todo cuando se manifiesta a través del sonido.

Podría reconocerse en este punto que, dada esta noción de escucha, todos los animales con facultad auditiva tendrían la misma capacidad para escuchar. Sin embargo, aunque ciertamente muchos animales oyen y reaccionan ante los sonidos del entorno, el modo en que el ser humano escucha es peculiar. En efecto, hombres y mujeres, al oír, intentan reconocer el sentido de lo captado por el oído. En este sentido, además de oír, el ser humano reviste cualitativamente su facultad auditiva, al punto de que, mediante ella, trata de ver la causa del sonido escuchado. Asimismo, en el desarrollo de la escucha, es decir, en la búsqueda del sentido a través del oído, el ser humano reconoce y distingue una forma del sonido que trae consigo significación y que proviene de un congénere: la palabra.

La escucha está vinculada al acontecimiento del lógos. Ello se debe a que la palabra no sólo impacta por el concepto que comporta. Las palabras implican una cierta sonoridad, poseen entonación que adviene al oído y disponen al oyente a captar el sentido de algo. Por ello puede decirse que el sentido de las palabras, es decir, aquello a lo que se refieren, comienza a esclarecerse en la escucha. Parecería, entonces, que la escucha recoge a la palabra y permite que la razón del oyente discierna el sentido de lo dicho por el hablante. Esta función de la escucha es de primer orden $\mathrm{y}$, por supuesto, constatable en la experiencia cotidiana. Sin embargo, quien esto suscribe considera que la escucha tiene un papel más fundamental que el de ser el canal que conduce un mensaje al entendimiento.

La escucha permite enterarse del entorno. La infinita gama de sonidos, concatenados todos en una sucesión que, a primera impresión, parecen no estar vinculados, logra enterar al individuo de que se halla en un mundo de infinitas expresividades. Todo cuanto pasa por la escucha, aun antes de ser asimilado como algo con sentido, brinda una certeza irrefutable: definitivamente, nunca 
se está solo. En el encuentro con el otro, la escucha se revela como algo aún más sorprendente. Si bien es cierto, como indicó Nicol en su Metafísica de la expresión, que incluso la presencia silenciosa del otro es expresiva ${ }^{13}$, acaso pueda señalarse que ello se debe a que en la interpretación que cada cual hace sobre la presencia ajena, ésta habla y es posible escuchar lo que aparentemente dice la pura presencia del otro. Esto implica que la escucha, aunque parece estar limitada al órgano auditivo, sin embargo, opera más allá de la recepción de ondas sonoras en el tímpano. Se escucha, incluso, el silencio; el silencio de la presencia ajena que puede no articular palabras hacia uno mismo y, no obstante, decir mucho mediante la ausencia de palabras. Escuchar, por tanto, va más allá de captar un mensaje significativo articulado mediante un sistema lingüístico y requiere de la atención presta ante el otro, con cuya presencia ya está hablando.

\section{La intuición-escucha}

Se ha tratado de mostrar que la escucha permite comprender el entorno sonoro, en general, las palabras que otro profiera, así como los silencios que ocurren en el encuentro con los demás. Pero, aunque pudiera parecer que la escucha es una actividad que realiza el ser humano de manera natural, en realidad se trata de una facultad que requiere cultivo, esfuerzo y práctica. Cabe sugerir, entonces, que hay que aprender a vivir escuchando. Este aprendizaje tiene que ver con no limitarse a tratar de hallar el sentido lógico, conceptualmente adecuado, de lo que el otro dice mediante sus palabras. Se trata de ir más allá: de captar aquello que se quiere decir a través ( $\mathrm{y}$, a veces, a pesar de) lo dicho. Esta forma de la escucha es la que se empeña por intuir lo que el otro, a su vez,

${ }^{13}$ Cf. Nicol. Op. Cit. pp. 118-119. 
ha vivido. Esta escucha que intuye al otro, más allá de los conceptos empleados, es a lo que se denomina aquí intuiciónescucha.

Por lo anterior, se puede postular que con la intuición-escucha es factible compenetrarse con el otro. Captar el torrente de vivencias que se le presentan y, sobre todo, comprender el modo en que interpreta $s u$ mundo y, por consiguiente, su modo de habitar en el mismo. Mediante la intuición-escucha es factible adentrarse en el carácter ajeno, mirar eso que no siempre queda dicho en la palabra compartida. ${ }^{14}$

Ahora bien, ¿cómo lograr el desarrollo de la intuición-escucha? Ciertamente, para alcanzar a ver lo vivido por otro, a través de sus palabras y sus silencios, no existe método específico. Sin embargo, la propia tradición filosófica enseña, desde antiguo, algunos caminos que pueden aplicarse en el presente para lograr ver a través de la escucha. Acaso el que pudiera considerarse un primer paso para desarrollar la intuición-escucha es una actividad que, aunque obvia, no es inútil recordar: guardar silencio. Esta guarda del silencio, en el encuentro con el prójimo, es una forma de dejar ser al otro en el modo en que se expresa. Este permitir que el interlocutor (se) exponga como crea conveniente es necesario para

${ }^{14}$ No quisiera pasar el dato de que mi propuesta de la intuición-escucha me parece muy cercana a la resonant understanding postulada por Cornelia Bruell, quien afirma lo siguiente: "En el momento del "entendimiento resonante", [...], podemos argumentar (siguiendo a Levinas) que la racionalidad del contenido y la simbolización pierden poder ante el significado del decir. Aquí, decir, refiere al acto de darse sin hacer que ello dependa de las consecuencias o la intención previa. [El texto original dice: In a moment of "resonant understanding", [...], we could argue (following Levinas), that the rationality of the content and symbolization loses power, whereas the meaning of saying, the act, gains power. Here, saying, relates to an act of giving without making it dependent on the consequences and an anticipated aim.]" Cornelia Bruell. "Resonant Understanding: Going beyond Self and Other" en Detlef Staude y Eckart Rushmann. Understanding the Other and Oneself. p. 133 La traducción es mía. 
poder ver lo que expresa, en la medida de lo posible, desde su punto de vista.

Derivado de la acción de guardar silencio en el encuentro dialógico con el otro, un segundo momento correspondería con procurar, también en la medida de lo posible, suspender el juicio sobre lo dicho por el otro. Se trataría del intento por no juzgar y, con ello, no alterar la vivencia expuesta por el otro mediante sus palabras y sus silencios. Naturalmente, no resulta posible eliminar los juicios que cada uno emite todo el tiempo, ${ }^{15}$ pero sí es posible esforzarse por procurar no asumir que el juicio que uno se formula en relación con lo declarado por otro es, de inicio, verdadero. Es un esfuerzo por intentar, literalmente, contenerse para permitir ser al otro. Esto supone una ardua labor, pero abriría la posibilidad de reforzar la empatía con el otro y, desde luego, de ver lo ocurrido como ha sido visto por el interlocutor.

Aunado a lo anterior, otro paso que se puede asumir para desarrollar la intuición-escucha, junto con la guarda del silencio y la suspensión del juicio ante lo dicho por el otro, es la atención sobre los gestos que emplea al hablar, los énfasis que se exponen en su discurso, los supuestos que asume y el reconocimiento de que

${ }^{15}$ Recuérdese que juicio es la facultad que asocia a un determinado sujeto con determinadas propiedades. Así, decir Alicia es una buena persona y Felipe tiene un automóvil, son dos ejemplos de juicio, aunque difieren por el tipo de atributo que se vincula con los respectivos sujetos. En este sentido, hay juicios descriptivos (como Felipe tiene un automóvil) que pueden ser reconocidos como verdaderos o falsos con la simple constatación en la experiencia, y hay juicios que podrían denominarse axiológicos pues establecen una valoración sobre determinados sujetos (como en el caso de Alicia es una buena persona). En este caso, la atribución de ser buena persona respecto del sujeto Alicia depende de varios factores que no siempre son contrastables con la experiencia inmediata. Este tipo de juicios son los que, con mayor frecuencia, se evalúa a las personas cotidianamente y, a partir de los cuales, se generan pareceres sobre ellas. Este tipo de juicios es el que hay que procurar suspender para desarrollar la intuiciónescucha. 
aquello que cuenta es lo que reconoce efectivamente, aunque deje de lado otras cosas. Hay que señalar que esta atención debe evitar interpretar los gestos y las omisiones de un modo $\mathrm{u}$ otro, $\mathrm{y}$ limitarse a verlos, como algo que presenta el interlocutor en lo que, de hecho, explícitamente expone. ${ }^{16}$ Es pertinente, pues, poner atención en lo que se insinúa o se manifiesta de manera implícita en lo declarado por el interlocutor.

Un ejemplo podrá ayudar a reforzar este punto. Supóngase que dos personas dialogan entre sí. Uno de ellos, le cuenta al otro una situación que ha vivido: resulta que el que narra su historia le cuenta a su interlocutor que recientemente ha tenido un problema con sus vecinos, debido a que no logran ponerse de acuerdo sobre lo que es más urgente de resolver en el edificio en el que cohabitan. Según este narrador, muchos vecinos consideran que es imperativo resolver el problema de la seguridad del edificio, pues afirman que los cerrojos de la puerta principal del edificio son poco eficientes y cualquiera podría irrumpir en el inmueble con consecuencias lamentables. El individuo que cuenta esto, por otra parte, considera que, aunque ello es importante, sin embargo, es más urgente reparar o renovar la instalación eléctrica porque, de lo contrario,

${ }^{16}$ En este punto pareciera haber una diferencia cualitativa respecto de la propuesta de asesoramiento filosófico que plantea Gerd Achenbach, para quien es menester no ir más allá de lo declarado explícitamente por el otro. Coincido plenamente con Achenbach en el punto, pero ello no implica no poner atención en lo que envuelve al discurso explícito por el otro y que se hace patente, de manera evidente, aunque no forme parte de las palabras proferidas por el interlocutor. Se trata de esforzarse por dejar ser y, por ende, ver como se presenta, al otro. Sobre la postura de Achenbach, $C f$. Samper, José Luis en "Apuntes sobre los supuestos de la práctica filosófica" en HASER. Revista Internacional de Filosofía Aplicada. № 5, 2014, pp. 17-18.

Disponible en: https://idus.us.es/xmlui/bitstream/handle/11441/58542/APUNTES\%20SOBRE\% 20LOS\%20SUPUESTOS\%20DE\%20LA\%20PR\%C3\%81CTICA.pdf?sequence =1\&isAllowed=y consultado en línea el 10 de noviembre de 2018 . 
podrían tener un problema con la electricidad que, a la postre, sería más complejo y costoso para ser resuelto. Si el que oye esta historia fuese alguien que intenta practicar la intuición-escucha, además de procurar no intervenir en la narración de su interlocutor, también habría de procurar no juzgar sobre lo que el otro evalúa (por ejemplo, conviene no juzgar algo como lo siguiente: "en realidad, los vecinos son quienes tienen razón" o algo como: "me parece que tienes razón tú, qué necios son tus vecinos"). Pero, además, en la atención prestada a lo dicho, podría comenzar a reconocerse lo no dicho en la narración. Algo evidente es que el interlocutor asume su postura porque, acaso, considera que es más urgente ese problema que observa $\mathrm{y}$, acaso, también parece creer que la solución es viable de manera efectiva. Por contraste, aunque no se declare explícitamente, el narrador de la historia parece suponer que sus vecinos no ven el problema más urgente $\mathrm{y}$, aparentemente, para él, pierden tiempo en algo que, según su convicción, es secundario. Todas estas implicaciones, naturalmente, no han sido explícitas, pero se asoman a través de lo dicho. Tener la atención puesta en ello permite ver el modo en que el otro interpreta su situación vital $\mathrm{y}$, consecuentemente, abre la posibilidad de reconocer que, tal vez, es por lo que asume como válido implícitamente que experimenta frustración al relacionarse con los demás en relación con una circunstancia como la descrita.

El ejercicio de atender lo no dicho en el discurso expuesto por un interlocutor sería lo haría posible comenzar a formularle preguntas que le permitan pensar sobre las razones que pudo haber asumido para actuar del modo en que actuó o para omitir ciertos comportamientos. Éstas tendrían que promover, en primer lugar, que el otro reflexione sobre los supuestos implícitos que asume para afirmar lo que sea que afirme. Pero, la clave de este preguntar radica en que se haya visto a partir de lo escuchado aquello que subyace en el discurso proferido, aunque no sea del todo patente para quien ha hablado. De aquí que, al formular preguntas, éstas 
provengan de la escucha que permite intuir $\mathrm{y}$, por ende, comprender al otro. Con lo hasta aquí descrito, parecería que Heráclito tiene razón: si no se sabe escuchar, difícilmente se puede hablar. En este contexto, podría decirse que, para poder dialogar con el otro ejercitándose en la intuición-escucha, es menester escuchar para ver al otro y, con ello, poder hablar con sentido sobre lo que le atañe.

Ahora bien, en el ejemplo propuesto se aprecian los pasos que podrían aplicarse para desarrollar la intuición-escucha en situaciones cotidianas. No obstante, dichos pasos $\mathrm{y}$, por consiguiente, la práctica de la intuición-escucha podría implementarse para circunstancias más complejas como, por ejemplo, el trato con personas que son poco proclives a conversar o que, incluso, padecen algún tipo de autismo. Ante una personalidad de ese tipo, se podría considerar que no hay diálogo $\mathrm{y}$, por lo mismo, que sería imposible ver, a través de la escucha de sus palabras, lo que ha vivido. No obstante, es conveniente sugerir que el diálogo no siempre debe ser verbal. Hay diálogos que se ofrecen sin mediación de la palabra, pero en la con-vivencia de los actos. Así, se puede estar con aquel que no habla y observar lo que hace para, a partir de la comprensión en silencio de lo que realiza, comenzar a reconocer lo que le parece importante, entretenido o rechazable. En este reconocimiento silencioso de la convivencia con el otro, también es menester procurar evitar formular un juicio valorativo y, más bien, observar lo que hace sin intervención de las propias creencias. Conviene señalar que, ante alguien que no acostumbra expresarse mucho a través de la palabra, las preguntas no suelen ser lo más adecuado para interactuar. Por tanto, en el reconocimiento silencioso de cuanto le interesa a quien no habla conviene ofrecer acompañamiento en el silencio. Es posible que, por ejemplo, en caso de hallarse con personas autistas, que lo que les guste sea, por ejemplo, dibujar, escuchar historias (cuentos, novelas) o música. Y, aunque no expresen lo que sientan o piensan 
de manera verbal, el puro hecho de que se encuentren en paz con quien se halla con ellos puede ser considerado como la expresión de que ahí, en esa situación, encuentran una serenidad y libertad para ser como son que muchas veces el mundo contemporáneo les impide. $^{17}$

Como se mencionó líneas atrás, la intuición-escucha no posee un método específico para ser desarrollada indefectiblemente. Sin embargo, los pasos que se han indicado hasta este punto para desarrollar la intuición-escucha, si bien podrían no ser los únicos, pueden ser considerados como los más elementales para el desarrollo de tal habilidad. No obstante, es importante señalar que la puesta en práctica de dichos pasos no es ni puede ser uniforme, sino que quien se quiera adentrar en ello dotará, sin lugar a dudas, de un modo peculiar el ejercicio de cada paso. Esto quiere decir que los actos de guardar silencio, suspender el juicio, poner atención a lo no dicho y formular preguntas respecto de esto último siempre serán llevados a la práctica de maneras distintas por quienes intenten ejercitarse en esto. Lo relevante es que se asuma la voluntad de procurar llevar a efectos tales ejercicios, si es que se desea intentar desarrollar la intuición-escucha. Además, quizá si alguien reconoce que otras prácticas filosóficas se parecen o,

${ }^{17}$ Definitivamente, uno de los campos potenciales de lo que aquí se propone como intuición-escucha tiene que ver con casos en los cuales los individuos no siempre emplean la palabra para expresarse. En esos casos, según las consideraciones que se plantean, hay que aprender a con-vivir en el silencio. Saber escuchar en la ausencia de las palabras es algo que conviene cultivar para lograr convivir con cuantos no saben, no pueden o no quieren hablar, pues será a través de otros medios como expresarán su peculiar forma de ser y es conveniente aprender a escucharlos. Se considera, por ello, que lo primero que hay que reconocer es que el asedio de la claridad mediante el discurso que fuerza a muchos a "integrarse" a la "normalidad" del uso del lenguaje hablado es algo que hay que cuestionar y comenzar a explorar caminos de expresión que van más allá del uso discursivo del lenguaje. El tema es sumamente fecundo, pero rebasa con creces los postulados elementales del presente artículo. 
incluso, rebasan lo que aquí se propone como intuición-escucha, ello permitirá enriquecer la propuesta esbozada, en el ánimo de procurar una mejor comprensión y compenetración con uno mismo y con los demás.

\section{Consideraciones finales sobre la intuición-escucha para la consultoría filosófica}

El atisbo de estas consideraciones son apenas una aproximación reflexiva sobre el trabajo que la consultoría filosófica puede llevar a cabo, en el encuentro con el otro. Estas ideas, además, se han retomado de la propia tradición filosófica, pues han estado presente en varios momentos de la historia del pensamiento filosófico. Sin duda, en el ejercicio mayéutico de Sócrates, aun sin ser explícito, puede apreciarse que hay un ejercicio de la intuición-escucha, pues el ateniense - según nos deja ver Platón en sus Diálogos- poseía esa enorme capacidad para ver y hacerle ver a su interlocutor el conjunto de creencias desde las cuales interpretaba su mundo. Preocupado porque ciertas creencias son nocivas para el propio individuo, Sócrates procuraba adentrarse en el otro para hacerle ver que cierta forma de mirar su relación con el entorno podría ser la causa de sus propios males. En este punto, el autor de estas líneas coincide con Pierre Hadot, quien reconoce en Sócrates al gran maestro de la ejercitación espiritual que le permite al individuo sosegar su ánimo y habitar la paz interior. Admite Pierre Hadot:

En el diálogo «socrático» el interlocutor de Sócrates no aprende nada, pues Sócrates no tiene intención de enseñarle nada: no hace más que repetir a quien quiera escucharle que lo único que sabe es que no sabe nada. Pero a la manera infatigable de un tábano, Sócrates acosa a sus interlocutores con preguntas que les ponen en cuestión, que les obligan a prestarse atención a sí mismo, a cuidarse de sí mismos [...]. La 
misión de Sócrates consiste pues en invitar a sus contemporáneos a examinar su consciencia, a cuidar de su proceso interior [...]. ${ }^{18}$

Por su parte, el estoicismo, heredero en cierto sentido de Sócrates, también propugna por el cuidado de lo único que el ser humano puede tener injerencia directa: el parecer que uno se forma a partir de lo que le ocurre. Una de las enseñanzas más importantes del estoicismo, y la cual puede invitar el filósofo, es a la de guardar silencio y comprender de qué manera y por qué razones se interpreta lo que le ocurre a uno mismo. Es interesante el planteamiento estoico porque intenta ayudar a los seres humanos a reconocer aquello sobre lo cual puede haber una verdadera intervención: el pensamiento de uno mismo y la manera de interpretar los hechos. A este respecto informa Hadot, comentando a Epicteto, lo siguiente:

El estoicismo tradicional opone [...] la esfera de la moralidad, es decir, de la libertad de elección entre el bien moral y el mal moral, y la esfera de las cosas «indiferentes», ni buenas ni malas moralmente, que son ajenas a nuestra libertad. Epicteto propone una diferenciación similar. A la esfera de la moralidad corresponde en su caso el ámbito de las cosas que no dependen de nosotros. Cabe constatar, por ejemplo, que la lista de cosas indiferentes, tal como las enumera el antiguo estoicismo (el cuerpo, nuestros bienes o la opinión que los demás tienen de nosotros) coincide exactamente con la lista de cosas que, según Epicteto, no dependen de nosotros, como la salud, la riqueza o la reputación. ${ }^{19}$

Como puede apreciarse, hay algunas consideraciones que ya presentaban las filosofías de antaño que, sin duda, pueden aprovecharse en el mundo contemporáneo. No se trata, desde luego, de traerlas al presente de manera literal, sin considerar el

\footnotetext{
${ }^{18}$ Hadot, Pierre: Ejercicios espirituales. Siruela, Madrid, 2006, pp. 34-35.

19 Hadot, Pierre. Manual para la vida feliz. Errata naturae editores, Madrid, 2006, pp. 91-92.
} 
contexto del mundo actual. Todo lo contrario. De lo que se trata es de que los profesionales de la filosofía reactualicen muchas de las prácticas que los filósofos, a lo largo de los siglos, han configurado en aras de alcanzar un modo de pensar independiente, pero en constante búsqueda del diálogo con los demás. Y es en esa praxis elemental del diálogo en donde la posibilidad de ver a través de la escucha adquiere mucha relevancia y vigencia. Si esta actividad, además, es factible para acompañar a quienes no son filósofos para que alcancen a ver, por sus propias reflexiones despertadas en la conversación con el filósofo, entonces el amor por el saber estará brindando un servicio fundamental a los individuos. Dicho servicio es el de coadyuvar a vivir sosegadamente, en paz, sin el vértigo al que continuamente empuja el mundo de los días que corren. La intuición-escucha, en este sentido, puede ser una herramienta eficaz para quienes se dedican al trabajo de la consultoría filosófica.

Por lo anterior, se puede considerar que el trabajo de los especialistas en este ámbito, es decir, en la consultoría filosófica, pueden retornar ( $\mathrm{y}$, de hecho, han retornado ya) hacia la práctica filosófica que no sólo reflexiona, sino que se vincula efectivamente con el otro mediante la apertura hacia la comprensión de su modo peculiar de ser. En este encuentro con el prójimo, el filósofo también logra la disposición a dejarse nutrir - y en este sentido verse a sí mismo - por la presencia del otro. Por lo mismo, la consultoría filosófica no puede pensarse unidireccionalmente. No es el filósofo el que "alivia" al no-filósofo. Más bien, el encuentro con el otro que el filósofo tiene es bidireccional, pues también el amante de la sabiduría amplía el conocimiento de sí mismo, en el reflejo de la mirada ajena. La intuición-escucha, por tanto, no sólo es un método para acceder al otro, sino también para acceder a uno mismo en comunión con el otro. En el acompañamiento o la consulta filosófica, los agentes son el filósofo y el no-filósofo, pues ambos, en su encuentro pueden mirarse internamente, más allá de lo que los propios términos verbales dejan ver. Por esto, la 
propuesta de la intuición-escucha parece pertinente, si bien no acabada y, por supuesto, abierta al diálogo, a la escucha y a la intuición.

\section{Bibliografía}

BERGSON, Henri. Intégrale des ouvres. Edición Kindle. Grands Classiques.com. 2015.

BERGSON, Henri. Introducción a la metafísica. / La risa. México: Porrúa, 2009.

BRENIFIER, Óscar. "¿Puede la filosofía convertirse en una práctica?”, Diálogo filosófico no. 68. 2007, pp. 217-228.

Disponible en:

https://www.ciudadredonda.org/admin/upload/files/1cr_t_adjuntos 269.pdf

HADOT, Pierre. Ejercicios espirituales.Madrid: Siruela, 2006.

HADOT, Pierre / Epicteto. Manual para la vida feliz. Madrid: Errata naturae editores, 2015.

HERÁCLITO. "Fragmentos" en Egger Lan, Conrado. Los filósofos presocráticos. Vol. 1. Madrid: Gredos, 2008.

LAHAV, Ran. Philosophical Practice: Have we gone far enough? Artículo disponible en: http://www.society-for-philosophy-inpractice.org/journal/pdf/9-2\%20013\%20Lahav\%20-

\%20Far\%20enough.pdf consultado en línea el 4 de enero de 2019. NICOL, Eduardo. Metafisica de la expresión.. México: FCE, 2003. NICOL, Eduardo. Crítica de la razón simbólica. México: FCE, 2006.

PLATÓN, Diálogos III (Fedón, Banquete, y Fedro). Madrid: Gredos, 2008.

SAMPER, José Luis. Lexica Lingua. Diccionario latino en línea. Dirección electrónica: www.lexica.linguax.com 
STAUDE, Detlef - RUSHMANN, Eckart. Understanding the Other and Oneself. UK: Cambridge Scholar Publishing, 2018. TERENCIO. Obras (La Andriana, El atormentado, El eunuco, Formión, La subora, Los hermanos). Madrid: Gredos, 2008. 
